Archive for

Organic Chemistry

Arkivoc 2020, part vii, 105-116

\title{
Synthesis and kinase inhibitory potencies of new pyrido[3,4-g]quinazolines substituted at the 8-position
}

\author{
Yannick J. Esvan, ${ }^{\text {a }}$ Béatrice Josselin, ${ }^{b}$ Blandine Baratte, ${ }^{b}$ Stéphane Bach, ${ }^{b}$ Sandrine Ruchaud, \\ Fabrice Anizon, ${ }^{a}$ Francis Giraud, ${ }^{* a}$ and Pascale Moreau*a \\ ${ }^{a}$ Université Clermont Auvergne, CNRS, SIGMA Clermont, ICCF, F-63000 Clermont-Ferrand, France \\ ${ }^{b}$ Sorbonne Université, CNRS, Plateforme de Criblage KISSf (Kinase Inhibitor Specialized Screening Facility), \\ FR2424, Station Biologique, Place Georges Teissier, \\ F-29688 Roscoff, France \\ Email: francis.giraud@uca.fr; pascale.moreau@uca.fr
}

Dedicated to Jan Bergman on the occasion of his $80^{\text {th }}$ birthday

Received 06-10-2020

Accepted 06-29-2020

Published on line $07-16-2020$

\section{Abstract}

As part of the structure-activity relationship study undertaken around the pyrido[3,4-g]quinazoline moiety, new derivatives substituted at the 8-position were synthesized and evaluated regarding their ability to inhibit various protein kinases (CDK5, CLK1, DYRK1A, CK1, GSK3). Most active compound exhibited a nanomolar potency toward CLK1, demonstrating that substitution at 8-position is compatible with CLK1 inhibition.
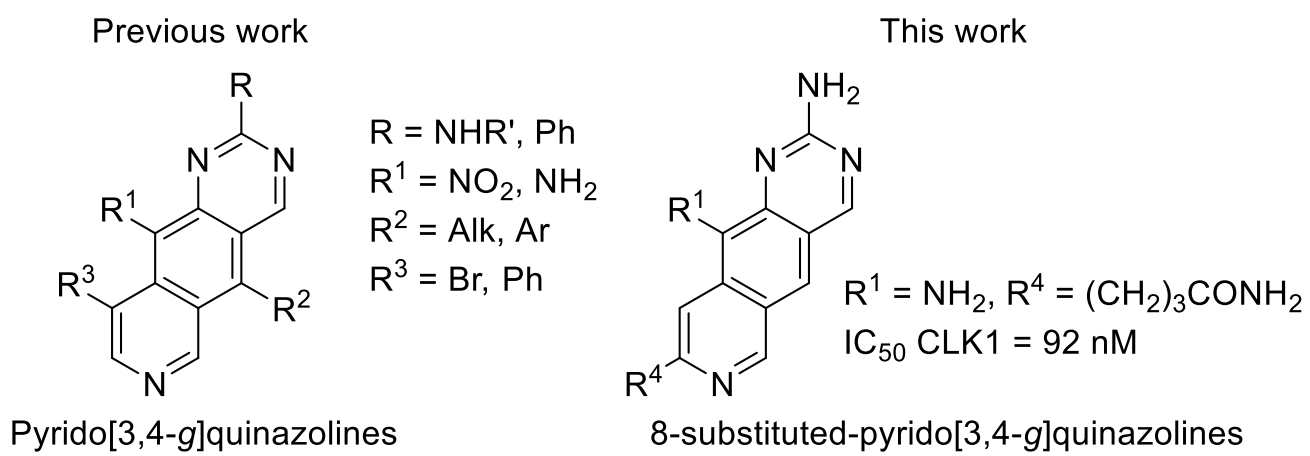

Keywords: Fused azines, isoquinolines, pyrimidines, pyridoquinazolines 


\section{Introduction}

A few years ago, as part of our program dedicated to the identification of new heteroaromatic compounds with kinase inhibitory potencies, we designed and synthesized a new pyrido[3,4-g]quinazoline series for the inhibition of CDC-like kinase 1 (CLK1)/Dual specificity tyrosine-phosphorylation-regulated kinase $1 A$ (DYRK1A). ${ }^{1}$ The structure-activity relationship (SAR) studies undertaken around this new series (Figure 1) showed that the kinase inhibition profile was highly dependent on the scaffold substitution. For example, while analogues diversely substituted at 2- and 10-positions were active toward CLK1/DYRK1A, the introduction of alkyl/aryl groups at the 5-position was detrimental to the inhibition of CLK1/DYRK1A in favour of the one of CDK5/GSK3. ${ }^{1-4}$ To complete this SAR study, we decided to focus our interest on the 8-position of the pyridoquinazoline scaffold (Figure 1), evaluating the impact of this structural modification on the biological activities.

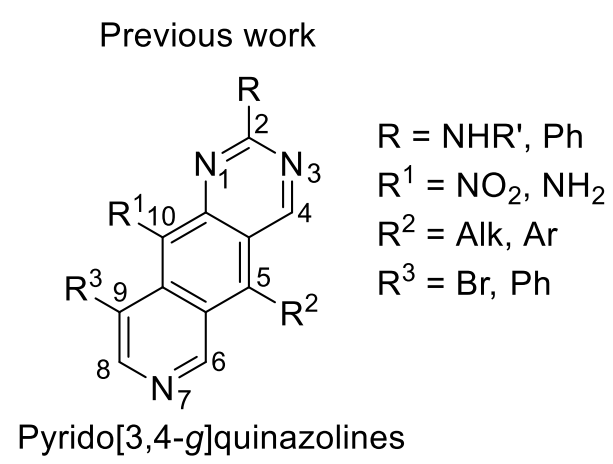

This work<smiles>[R]c1cc2c([R])c3nc(N)ncc3cc2cn1</smiles>

8-substituted-pyrido[3,4-g]quinazolines

Figure 1. Structural modifications performed in the pyrido[3,4-g]quinazoline series as part of our structureactivity relationship study.

As previously reported, ${ }^{1-4}$ the synthetic pathway was based on the preparation of a tetrasubstituted benzene derivative $\mathbf{A}$, with substituents at the 1- and 2-positions used to construct the isoquinoline moiety (after Sonogashira cross-coupling with TMS-acetylene and subsequent cyclization in the presence of ammonia), while those at the 4- and 5-positions allowed the formation of the aminopyrimidine moiety (after oxidation, nitration and condensation with diversely substituted guanidine/amidine derivatives) (Scheme 1).
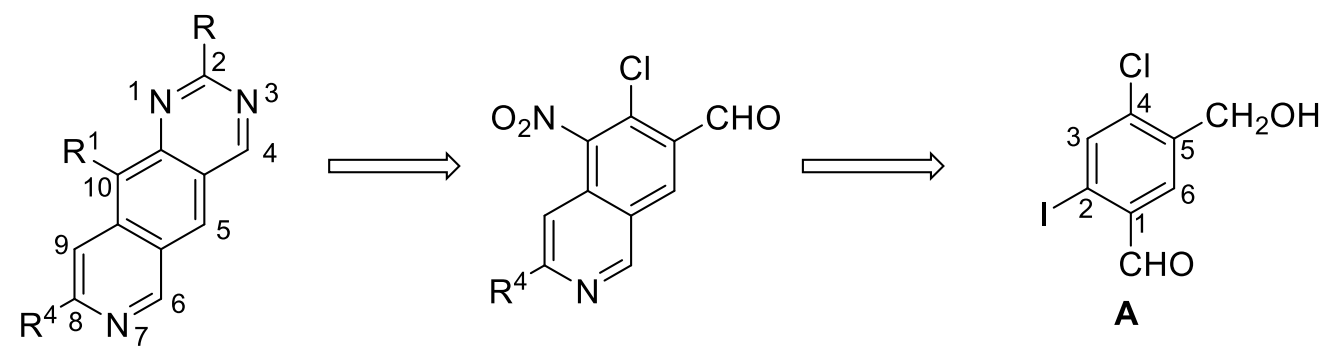

$$
\begin{gathered}
\text { Pyrido[3,4-g]quinazolines } \\
\mathrm{R}=\mathrm{NHR}^{\prime}
\end{gathered}
$$

Scheme 1. Synthetic strategy used to prepare the pyrido[3,4-g]quinazoline tricyclic scaffold. 
To generate a new compound library, the functionalization of the 8-position was achieved via a similar approach using, in the Sonogashira coupling step, various alkynes bearing functional groups that could allow post-modifications after the formation of the tricyclic system.

\section{Results and Discussion}

Our first idea to prepare pyrido[3,4-g]quinazolines bearing aminoalkyl side chains at the 8-position was the use, in the Sonogashira coupling step, of a but-1-yne derivative bearing at the 4-position a phthalimide protected amine precursor. Therefore compound $\mathbf{A}$ was reacted with 2-(but-3-yn-1-yl)isoindoline-1,3-dione ${ }^{5}$ in the presence of $\mathrm{PdCl}_{2}\left(\mathrm{PPh}_{3}\right)_{2}$, Cul and $\mathrm{Et}_{3} \mathrm{~N}$ in DMF to afford 1 in $73 \%$ yield. ${ }^{6}$ Compound 1 was then cyclized to the corresponding isoquinoline 2 in the presence of ammonia in methanol ${ }^{7}$ before primary alcohol oxidation with $\mathrm{MnO}_{2}{ }^{8}$, leading to chloroaldehyde 3 (Scheme 2). The next step was the introduction of a nitro group at the 5-position of the isoquinoline moiety in order to allow subsequent formation of the aminopyrimidine moiety. Unfortunately, the nitro derivative was never obtained due to a preferred nitration of the phthalimide moiety.

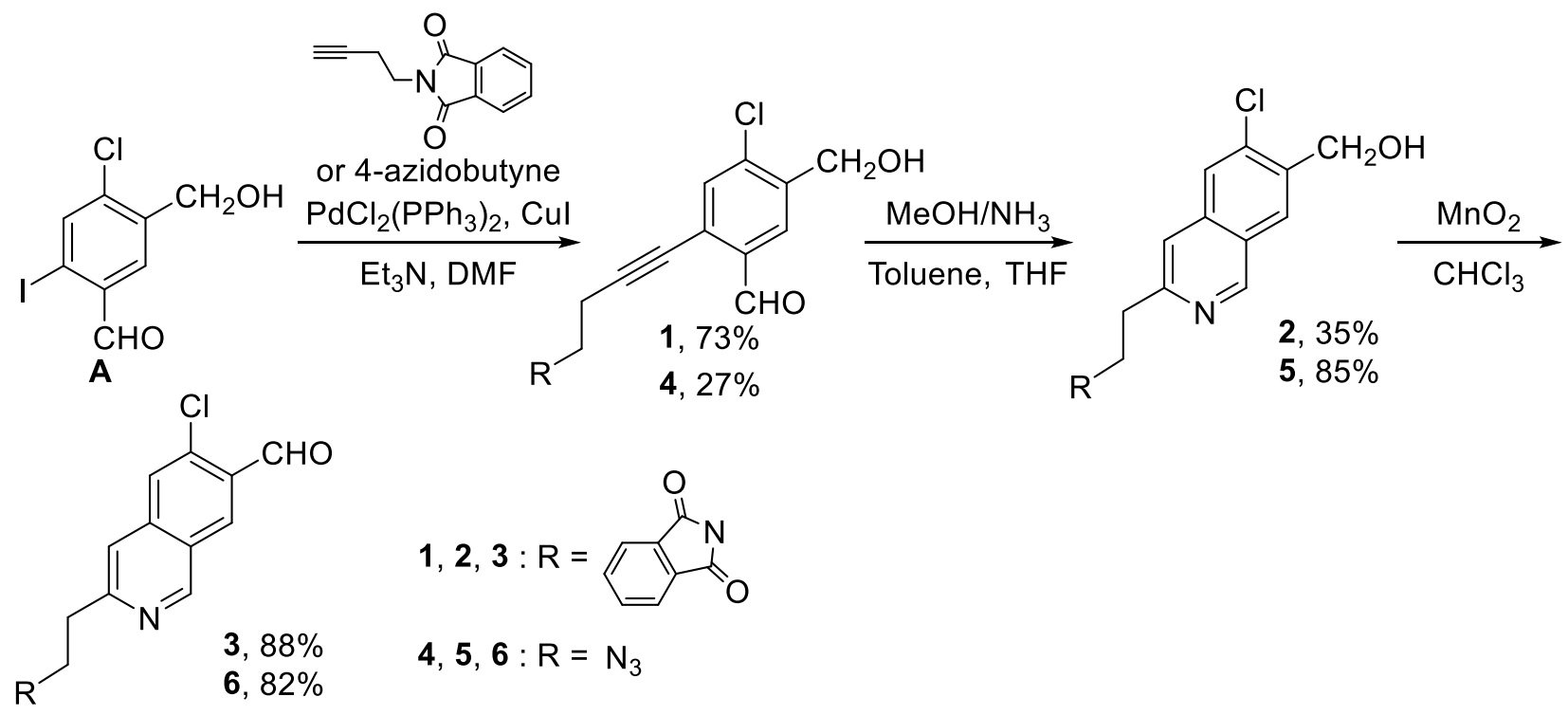

Scheme 2. Phthalimido/azido strategy: synthesis of compounds $\mathbf{3}$ and $\mathbf{6 .}$

Thus, we decided to use an azido group as amine precursor. The synthesis of the corresponding isoquinolines $\mathbf{5 / 6}$ was performed via the same synthetic sequence using 4-azidobut-1-yne ${ }^{9}$ as alkyne partner in the first step (Scheme 2). Regrettably, compound 6 was unstable under the nitration conditions used. Formation of the aminopyrimidine ring directly from $\mathbf{3}$ or $\mathbf{6}$ in the presence of guanidine carbonate, without activation of the isoquinoline by an electron-withdrawing group, was unsuccessful.

Because of these failures, the preparation of another intermediate, an isoquinoline bearing at the 3position an ethyl side chain bearing a mesylate terminal group, likely to undergo a nucleophilic displacement with amines, was considered. Therefore, compound A primary alcohol was protected as a THP group before Sonogashira coupling in the presence of but-3-yn-1-ol leading to 8 that was cyclized to the corresponding isoquinoline 9 (Scheme 3). Finally, chloroaldehyde 12 was prepared by mesylation of the primary alcohol, 
cleavage of the THP group under mild acidic conditions, and oxidation. In this case, the nitration reaction led to the attempted product 13 in $77 \%$ yield. In the last step, the formation of the aminopyrimidine moiety performed in the presence of guanidine carbonate, led to tricyclic compound 14. Basic conditions used also led to an elimination reaction (Scheme 3). Due to low solubility of $\mathbf{1 4}$, all further double bond transformations assayed (hydroboration, hydroamination, oxidative cleavage) were unsuccessful.

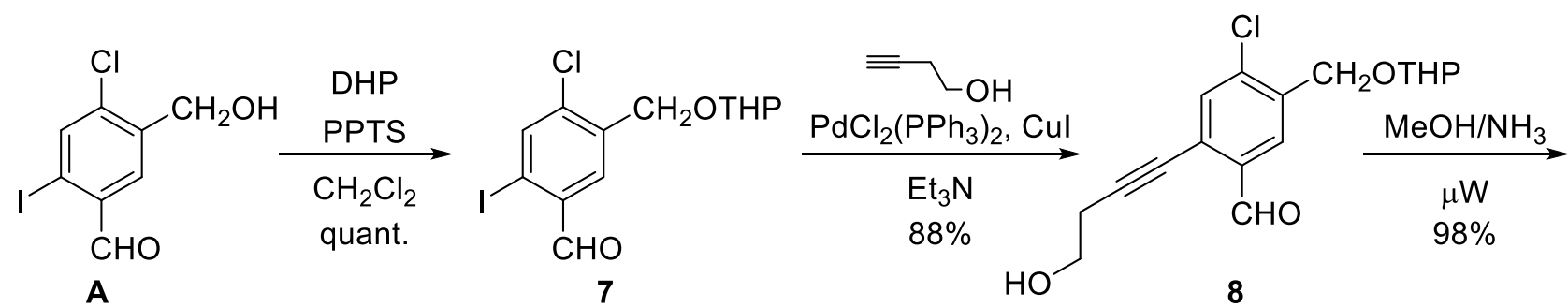

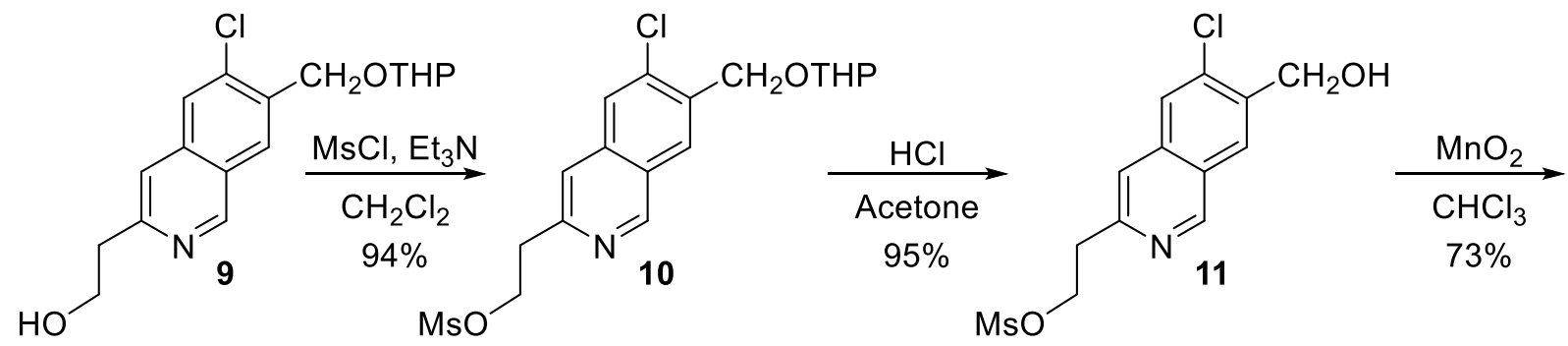<smiles>COCCc1cc2cc(Cl)c(C=O)cc2cn1</smiles><smiles>COCCc1cc2c([N+](=O)[O-])c(Cl)c(C=O)cc2cn1</smiles><smiles>C=Cc1cc2c([N+](=O)[O-])c3nc(N)ncc3cc2cn1</smiles>

Scheme 3. Mesylate strategy: synthesis of compound 14.

Another strategy was to introduce a side chain bearing a nitrile group, that could be reduced to the corresponding amino analogue or hydrolyzed to give the corresponding amide. Therefore, compound $\mathbf{A}$ was reacted with pent-4-ynenitrile under Sonogashira coupling conditions to give $\mathbf{1 5}$ that was cyclized to the corresponding isoquinoline $\mathbf{1 6}$ in the presence of ammonia in methanol under microwave irradiation before primary alcohol oxidation leading to chloroaldehyde $\mathbf{1 7}$ (Scheme 4). Again, next step was the introduction of a nitro group at the 5-position of the isoquinoline moiety. Despite numerous efforts using various nitration conditions $\left(\mathrm{HNO}_{3}, \mathrm{Ac}_{2} \mathrm{O}, \mathrm{AcOH}^{10}\right.$ or $\mathrm{KNO}_{3}, \mathrm{H}_{2} \mathrm{SO}_{4} / \mathrm{TFA}^{11}$ or $\mathrm{AgNO}_{3}, \mathrm{NBS}^{12}$ or $\mathrm{HNO}_{3}, \mathrm{P}_{2} \mathrm{O}_{5} / \mathrm{H}_{2} \mathrm{SO}_{4}-\mathrm{SiO}_{2}{ }^{13,14}$ or $\mathrm{N}_{2} \mathrm{O}_{4}{ }^{15}$ or $\mathrm{NO}_{2} \mathrm{BF}_{4}{ }^{16}$ or $\mathrm{KNO}_{3} / \mathrm{H}_{2} \mathrm{SO}_{4}{ }^{17}$ ), we never managed to prepare intermediate $\mathrm{B}$. Instead, nitro analogue 18 exhibiting an amide function was obtained in $85 \%$ yield (Scheme 4). However, as compound 18 could lead to new 8-substituted pyrido[3,4-g]quinazolines, the synthesis was carried out to give the tricyclic compounds 19 and $\mathbf{2 0}$ which were obtained after condensation with guanidine carbonate and subsequent reduction of the nitro group, as already described (Scheme 4). ${ }^{1}$ 
<smiles>N#CCCC#Cc1cc(Cl)c(CO)cc1C=O</smiles><smiles>CO[Mg]</smiles>

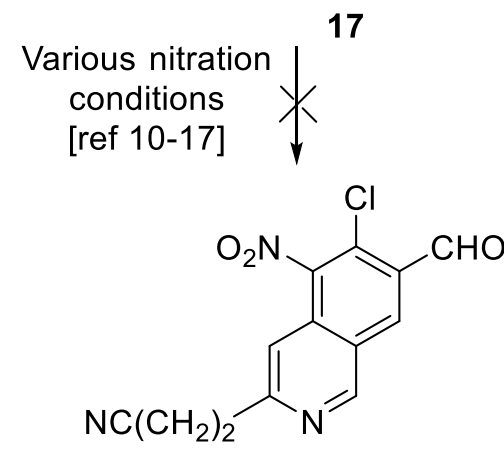

Intermediate B

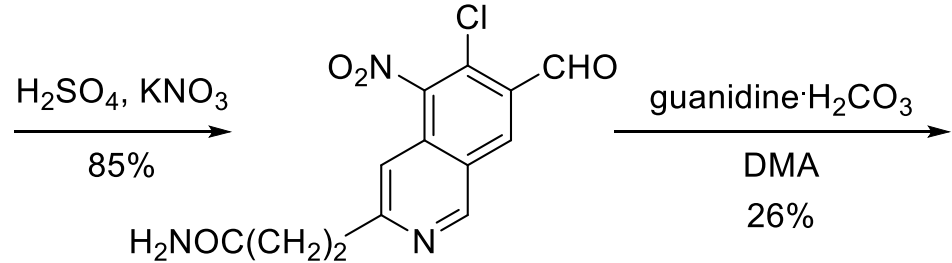

18

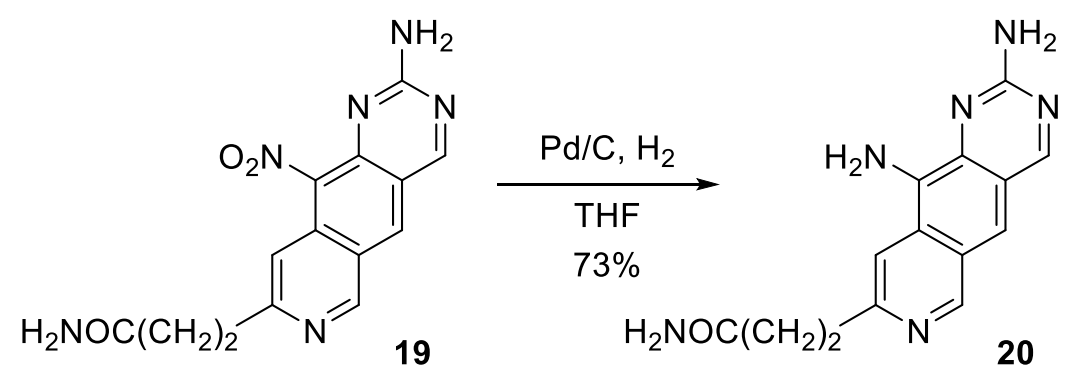

Scheme 4. Nitrile strategy: synthesis of compounds 19 and 20.

Tricyclic compounds 14, 19 and 20 were then evaluated toward a small panel of protein kinases (CDK5, CLK1, DYRK1A, CK1 and GSK3) using similar procedures as previously described. ${ }^{4,18}$ As shown in Table 1, most active compounds were 14 and 20 with interesting $I C_{50}$ values of $111 \mathrm{nM}$ and $92 \mathrm{nM}$, respectively, toward CLK1.

Table 1. Kinase inhibition assays (\% residual kinase activity)

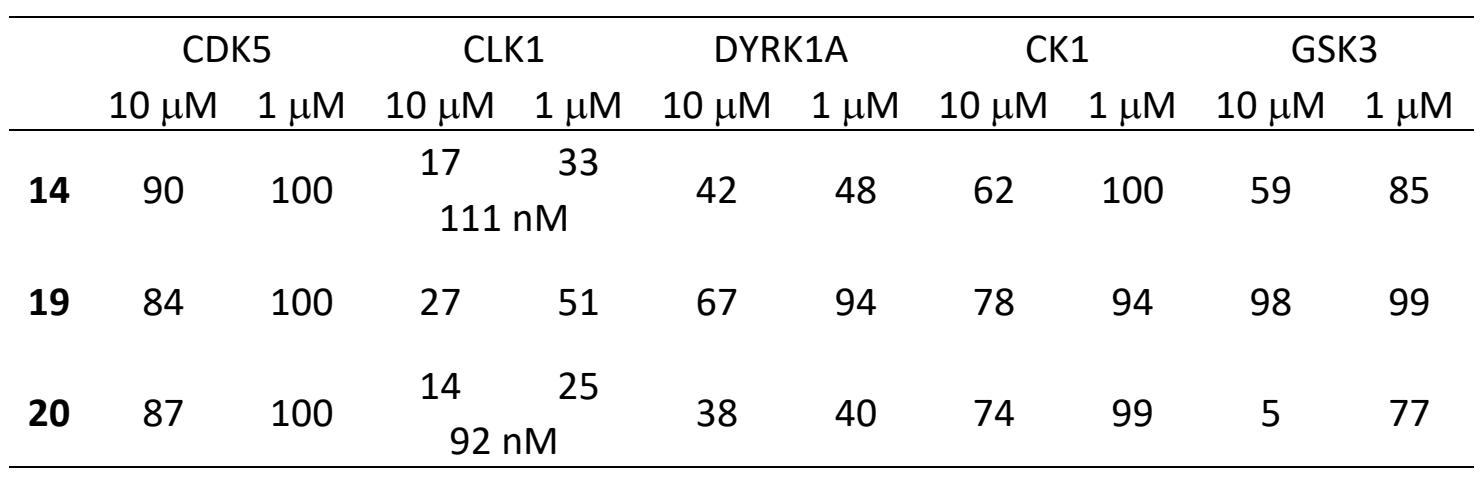

$\mathrm{IC}_{50}$ values were determined when the residual kinase activity was $\leq 35 \%$ at a compound concentration of $1 \mu \mathrm{M}$. Kinase activities were assayed in triplicate. Typically, the standard deviation of single data points was below $10 \%$. Assays for $\mathbf{1 9}$ and 20 were performed using a ${ }^{32} \mathrm{P}$ radioassay in the presence of $15 \mu \mathrm{M}$ ATP while 14 testing was carried out using the ADP-Glo assay in the presence of $10 \mu \mathrm{M}$ ATP. 


\section{Conclusions}

In conclusion, various synthetic strategies were carried out to introduce a functionalized side chain at the 8position of pyrido[3,4-g]quinazoline moiety. The use of the mesylate approach led to vinyl derivative $\mathbf{1 4}$ while the nitrile approach allowed the preparation of propionamides $\mathbf{1 9}$ and $\mathbf{2 0}$. The evaluation of these new diversely substituted compounds toward five protein kinases showed that compounds $\mathbf{1 4}$ and $\mathbf{2 0}$ were potent inhibitors of CLK1 with sub-micromolar/nanomolar potencies. Altogether, the results obtained demonstrated that the substitution at the 8-position of this tricyclic heteroaromatic scaffold is compatible with potent kinase inhibition.

\section{Experimental Section}

General. Starting materials were obtained from commercial suppliers and used without further purification. Experiments under microwave irradiation were performed using a CEM Discover Benchmate apparatus. IR spectra were recorded on a PerkinElmer spectrum $65 \mathrm{FT}-\mathrm{IR}$ spectrometer $\left(\bar{v}\right.$ in $\left.\mathrm{cm}^{-1}\right)$. NMR spectra, performed on a Bruker Avance $400\left({ }^{1} \mathrm{H}: 400 \mathrm{MHz},{ }^{13} \mathrm{C}: 100 \mathrm{MHz}\right)$, are reported in ppm using the solvent residual peak as an internal standard; the following abbreviations are used: singlet (s), doublet (d), triplet (t), quadruplet (q), multiplet $(\mathrm{m})$, broad signal (br s). High resolution mass spectra (ESI+) were determined on a high-resolution Waters Micro Q-ToF apparatus (UCA-Partner, Université Clermont Auvergne, Clermont-Ferrand, France). Chromatographic purifications were performed by column chromatography using 40-63 $\mu \mathrm{m}$ silica gel. Reactions were monitored by TLC using fluorescent silica gel plates (60 F254 from Merck). Melting points were measured on a Stuart SMP3 apparatus. The purity of final compound 19 was established to be $>95 \%$ by HPLC analysis using a Hitachi liquid chromatograph (Oven 5310, $30^{\circ} \mathrm{C}$; Pump 5160; DAD detector 5430) and a C18 Acclaim column $(4.6 \mathrm{~mm} \times 250 \mathrm{~mm}, 5 \mu \mathrm{m}, 120 \AA$ A). Detection wavelength was $240 \mathrm{~nm}$ and flow rate 0.5 $\mathrm{mL} / \mathrm{min}$. Elution was performed with water / acetonitrile eluent 50/50.

4-Chloro-2-[4-(1,3-dioxoisoindolin-2-yl)but-1-yn-1-yl]-5-(hydroxymethyl)benzaldehyde (1). To a solution of A $(3.26 \mathrm{~g}, 11 \mathrm{mmol})$ in DMF $(5 \mathrm{~mL})$, under argon atmosphere, were successively added Cul (230 mg, $1.21 \mathrm{mmol})$, $\mathrm{PdCl}_{2}\left(\mathrm{PPh}_{3}\right)_{2}(386 \mathrm{mg}, 0.55 \mathrm{mmol}), \mathrm{Et}_{3} \mathrm{~N}(2.23 \mathrm{~mL}, 16.5 \mathrm{mmol})$ and 2-(but-3-yn-1-yl)isoindoline-1,3-dione (2.50 $\mathrm{g}, 12.54 \mathrm{mmol})$. The mixture was stirred at $40{ }^{\circ} \mathrm{C}$ for $16 \mathrm{~h}$. After cooling, water was added before extraction with EtOAc. Organic layers were dried $\left(\mathrm{MgSO}_{4}\right)$, filtered, concentrated under reduced pressure and the crude material was purified by flash chromatography using EtOAc/cyclohexane (4:6) yielding compound 1 (2.97 g, $8.07 \mathrm{mmol}, 73 \%)$ as a yellow solid. TLC $\mathrm{R}_{f}=0.46$ (EtOAc/cyclohexane 4:6). ${ }^{1} \mathrm{H}$ NMR (400 MHz, DMSO- $\left.d_{6}\right) 2.92$ $(\mathrm{t}, J 6.8 \mathrm{~Hz}, 2 \mathrm{H}), 3.89(\mathrm{t}, J 6.4 \mathrm{~Hz}, 2 \mathrm{H}), 4.56(\mathrm{~d}, J 6.0 \mathrm{~Hz}, 2 \mathrm{H}), 5.61(\mathrm{t}, J 5.6 \mathrm{~Hz}, 1 \mathrm{H}), 7.51(\mathrm{~s}, 1 \mathrm{H}), 7.84-7.91(\mathrm{~m}, 4 \mathrm{H})$, $7.94(\mathrm{~s}, 1 \mathrm{H}), 10.23(\mathrm{~s}, 1 \mathrm{H}) .{ }^{13} \mathrm{C}$ NMR $\left(100 \mathrm{MHz}\right.$, DMSO-d $\left.d_{6}\right) 18.9,36.0,59.8\left(\mathrm{CH}_{2}\right), 76.4,95.3\left(\mathrm{C}_{\text {alkyne }}\right), 123.1(2$ $\left.\mathrm{CH}_{\text {pht }}\right), 126.0,132.9$ ( $\left.\mathrm{CH}_{\text {arom }}\right), 134.6\left(2 \mathrm{CH}_{\text {pht }}\right), 125.3,131.5\left(2 \mathrm{C}_{\mathrm{pht}}\right), 134.1,136.6,140.8$ ( $\left.\mathrm{C}_{\text {arom }}\right), 167.7\left(2 \mathrm{CO}_{\text {pht }}\right)$, 190.5 (CHO). Mp: $162-164{ }^{\circ} \mathrm{C}$. IR (ATR) 3661-2968, $2100-2000,1766,1702,1063 \mathrm{~cm}^{-1}$. HRMS (ESI+) calcd for $\mathrm{C}_{20} \mathrm{H}_{15}{ }^{35} \mathrm{CINO}_{4}(\mathrm{M}+\mathrm{H})^{+} 368.0684$, found 368.0692 .

2-\{2-[6-Chloro-7-(hydroxymethyl)isoquinolin-3-yl]ethyl\}isoindoline-1,3-dione (2). In a CEM Microwave tube, $\mathrm{NH}_{3} / \mathrm{MeOH}(7 \mathrm{~N})(4.8 \mathrm{~mL})$ was added to $1(660 \mathrm{mg}, 1.795 \mathrm{mmol})$. The tube was irradiated at $75 \mathrm{~W}$ for $15 \mathrm{~min}$ at $130{ }^{\circ} \mathrm{C}$ in a microwave oven. The solvent was removed under reduced pressure. The crude product was purified by flash chromatography using EtOAc to yield compound $2(394 \mathrm{mg}, 1.074 \mathrm{mmol}, 60 \%)$ as a beige solid. TLC $R_{f}=0.34$ (EtOAc/cyclohexane 7:3). ${ }^{1} \mathrm{H}$ NMR (400 MHz, DMSO-d $\left.d_{6}\right) 3.18$ (t, J 7.2 Hz, 2H), 4.00 (t, J 6.8 $\mathrm{Hz}, 2 \mathrm{H}), 4.70(\mathrm{~d}, J 6.4 \mathrm{~Hz}, 2 \mathrm{H}), 5.61(\mathrm{t}, J 5.6 \mathrm{~Hz}, 1 \mathrm{H}), 7.65(\mathrm{~s}, 1 \mathrm{H}), 7.83(\mathrm{~m}, 4 \mathrm{H}), 7.99(\mathrm{~s}, 1 \mathrm{H}), 8.19(\mathrm{~s}, 1 \mathrm{H}), 9.24(\mathrm{~s}$, 
1H). ${ }^{13} \mathrm{C}$ NMR (100 MHz, DMSO-d $\left.d_{6}\right) 35.8,37.7,60.5\left(\mathrm{CH}_{2}\right), 117.5,123.0\left(2 \mathrm{CH}_{\text {pht }}\right), 125.5,126.1,134.3\left(2 \mathrm{CH}_{\text {pht }}\right)$, 151.8 ( $\left.\mathrm{CH}_{\text {arom }}\right), 125.3,131.6$ (2 C $\left.\mathrm{pht}\right), 134.3,135.4,138.6,152.2$ (C $\left.\mathrm{C}_{\text {arom }}\right), 167.7$ (2 $\left.\mathrm{CO}_{\text {pht }}\right) . \mathrm{Mp}: 212-214{ }^{\circ} \mathrm{C} . \mathrm{IR}$ (ATR) $3452-3250,2925,1759,1696,1451,1090 \mathrm{~cm}^{-1}$. HRMS (ESI+) calcd for $\mathrm{C}_{20} \mathrm{H}_{16}{ }^{35} \mathrm{CIN}_{2} \mathrm{O}_{3}(\mathrm{M}+\mathrm{H})^{+} 367.0844$, found 367.0833 .

6-Chloro-3-[2-(1,3-dioxo-1,3-dihydro-2H-isoindol-2-yl)ethyl]isoquinolin-7-carbaldehyde (3). To a solution of 2 (207.2 mg, $0.565 \mathrm{mmol})$ in $\mathrm{CHCl}_{3}(8 \mathrm{~mL})$ was added $\mathrm{MnO}_{2}(147.3 \mathrm{mg}, 1.695 \mathrm{mmol})$. The mixture was stirred at reflux for $18 \mathrm{~h}$ with adding of two more equivalents of $\mathrm{MnO}_{2}(98.2 \mathrm{mg}, 1.129 \mathrm{mmol})$ after $2 \mathrm{~h}$ of reflux. After cooling, filtration of the reaction mixture through a pad of Celite ${ }^{\circledR}$ and washing with EtOAc, the filtrate was concentrated in vacuo. The crude material was triturated with pentane yielding compound $3(182.4 \mathrm{mg}, 0.500$ mmol, 88\%) after filtration as a beige solid. TLC $\mathrm{R}_{f}=0.48$ (EtOAc/cyclohexane 5:5). RMN ${ }^{1} \mathrm{H}(400 \mathrm{MHz}$, DMSO$\left.d_{6}\right) 3,23(\mathrm{t}, J 7.2 \mathrm{~Hz}, 2 \mathrm{H}), 4.02(\mathrm{t}, J 6.8 \mathrm{~Hz}, 2 \mathrm{H}), 7.77(\mathrm{~s}, 1 \mathrm{H}), 7.83(\mathrm{~m}, 4 \mathrm{H}), 8.15(\mathrm{~s}, 1 \mathrm{H}), 8,72(\mathrm{~s}, 1 \mathrm{H}), 9,45(\mathrm{~s}, 1 \mathrm{H})$, $10,40(s, 1 H) .{ }^{13} \mathrm{C} N M R\left(100 \mathrm{MHz}, \mathrm{DMSO}-d_{6}\right) 36.0,37.5\left(\mathrm{CH}_{2}\right), 117.8,123.0\left(2 \mathrm{CH}_{\text {pht }}\right), 127.5,132.5,134.4(2$ $\left.\mathrm{CH}_{\text {pht }}\right), 154.1$ ( $\left.\mathrm{CH}_{\text {arom }}\right), 101.1,124.6,130.6,131.5$ (2 $\left.\mathrm{C}_{\text {pht }}\right), 138.5,155.6$ ( $\left.\mathrm{C}_{\text {arom }}\right), 167.7$ (2 $\left.\mathrm{CO}_{\text {pht }}\right), 189.4$ (CHO). Mp: $225-227{ }^{\circ} \mathrm{C}$. IR (ATR) 2861, 1761, 1690, 1616, 1452, $1100 \mathrm{~cm}^{-1}$ HRMS (ESI+) calcd for $\mathrm{C}_{21} \mathrm{H}_{18}{ }^{35} \mathrm{CIN}_{2} \mathrm{O}_{4}$ $(\mathrm{M}+\mathrm{MeOH}+\mathrm{H})^{+} 397.0950$, found 397.0941.

2-(4-Azidobut-1-yn-1-yl)-4-chloro-5-(hydroxymethyl)benzaldehyde (4). Using standard procedure as described, ${ }^{1} \mathrm{~A}$ (1.426 g, $\left.4.81 \mathrm{mmol}\right)$, Cul (36 mg, $\left.0.192 \mathrm{mmol}\right), \mathrm{PdCl}_{2}\left(\mathrm{PPh}_{3}\right)_{2}(67 \mathrm{mg}, 0.096 \mathrm{mmol}), \mathrm{Et}_{3} \mathrm{~N}(20 \mathrm{~mL})$ and 4-azidobutyne $(1.143 \mathrm{~g}, 12.02 \mathrm{mmol})$ were mixed together and heated at $50{ }^{\circ} \mathrm{C}$ overnight. Flash chromatography using $\mathrm{CH}_{2} \mathrm{Cl}_{2}$ yielded compound 4 (343 mg, $1.30 \mathrm{mmol}, 27 \%$ ) as a pale yellow powder. TLC $\mathrm{R}_{f}=$ 0.28 (EtOAc/cyclohexane 1:3). ${ }^{1} \mathrm{H}$ NMR (400 MHz, DMSO-d $\left.d_{6}\right) 2.85(\mathrm{t}, J 6.4 \mathrm{~Hz}, 2 \mathrm{H}), 3.59(\mathrm{t}, J 6.4 \mathrm{~Hz}, 2 \mathrm{H}), 4.59$ (d, J $6.0 \mathrm{~Hz}, 2 \mathrm{H}), 5.66(\mathrm{t}, J 6.0 \mathrm{~Hz}, 1 \mathrm{H}), 7.65(\mathrm{~s}, 1 \mathrm{H}), 7.99(\mathrm{~s}, 1 \mathrm{H}), 10.39(\mathrm{~s}, 1 \mathrm{H}) .{ }^{13} \mathrm{C} \mathrm{NMR}\left(100 \mathrm{MHz}, \mathrm{DMSO}-d_{6}\right) 20.1$, 48.9, $59.8\left(\mathrm{CH}_{2}\right), 76.4,95.9$ (C alkyne), 126.0, $132.9\left(\mathrm{CH}_{\text {arom }}\right), 125.5,134.3,136.8,141.0$ (C arom), 190.7 (CHO). Mp: 69-70 ${ }^{\circ} \mathrm{C}$. IR (ATR) 3667-2596, 2106, 1688, 1593, 1459, $1248 \mathrm{~cm}^{-1}$. HRMS (ESI+) calcd for $\mathrm{C}_{12} \mathrm{H}_{11}{ }^{35} \mathrm{CIN}_{3} \mathrm{O}_{2}(\mathrm{M}+\mathrm{H})^{+}$ 264.0534 , found 264.0531.

[3-(2-Azidoethyl)-6-chloroisoquinolin-7-yl]methanol (5). Using similar procedure as described for 2: 4 (325 $\mathrm{mg}, 1.233 \mathrm{mmol}$ ) and $\mathrm{NH}_{3} / \mathrm{MeOH}(3.52 \mathrm{~mL}, 24.65 \mathrm{mmol})$ were irradiated at $75 \mathrm{~W}$ and $130{ }^{\circ} \mathrm{C}$ in a sealed tube for $15 \mathrm{~min}$ in a microwave oven. After evaporation of the reaction mixture, flash chromatography using EtOAc/cyclohexane 7:3 to 9:1 yielded compound $5(277.5 \mathrm{mg}, 1.056 \mathrm{mmol}, 85 \%)$ as a beige solid. $\mathrm{TLC} \mathrm{R}_{f}=0.25$ (EtOAc/cyclohexane 7:3). ${ }^{1} \mathrm{H}$ NMR (400 MHz, DMSO-d 6 ) $3.14(\mathrm{t}, J 6.4 \mathrm{~Hz}, 2 \mathrm{H}), 3.79(\mathrm{t}, J 6.4 \mathrm{~Hz}, 2 \mathrm{H}), 4.72(\mathrm{~d}, J 6.4$ $\mathrm{Hz}, 2 \mathrm{H}), 5.66(\mathrm{t}, J 5.2 \mathrm{~Hz}, 1 \mathrm{H}), 7.71(\mathrm{~s}, 1 \mathrm{H}), 8.05(\mathrm{~s}, 1 \mathrm{H}), 8.22(\mathrm{~s}, 1 \mathrm{H}), 9.34(\mathrm{~s}, 1 \mathrm{H}) .{ }^{13} \mathrm{C} N M R\left(100 \mathrm{MHz}, \mathrm{DMSO}-d_{6}\right)$ 36.6, 50.0, $60.5\left(\mathrm{CH}_{2}\right), 117.8,125.52,126.1,152.02\left(\mathrm{CH}_{\text {arom }}\right), 125.50,134.5,135.4,138.8,152.00\left(\mathrm{C}_{\text {arom }}\right) . \mathrm{Mp}$ : 111-112 ${ }^{\circ} \mathrm{C}$. IR (ATR) 3524-2439, 2103, 1633, 1593, 1453, $1265 \mathrm{~cm}^{-1}$. HRMS (ESI+) calcd for $\mathrm{C}_{12} \mathrm{H}_{12}{ }^{35} \mathrm{CIN}_{4} \mathrm{O}$ $(\mathrm{M}+\mathrm{H})^{+}$263.0694, found 263.0692 .

3-(2-Azidoethyl)-6-chloroisoquinoline-7-carbaldehyde (6). Using similar procedure as described for 3: 5 (275.4 $\mathrm{mg}, 1.048 \mathrm{mmol}$ ) and $\mathrm{MnO}_{2}\left(364 \mathrm{mg}, 4.193 \mathrm{mmol}\right.$ ) were heated in $\mathrm{CHCl}_{3}(10 \mathrm{~mL})$ at reflux for $6 \mathrm{~h}$. $100 \mathrm{mg}$ of $\mathrm{MnO}_{2}$ were added and heating was continued overnight to completion. Filtration of the mixture over Celite pad and washing with EtOAc afforded after evaporation of the filtrate compound $6(225 \mathrm{mg}, 0.865 \mathrm{mmol}$, $82 \%)$ as a yellow powder. TLC Rf $=0.65$ (EtOAc/cyclohexane 1:1). ${ }^{1} \mathrm{H}$ NMR (400 MHz, DMSO- $\left.d_{6}\right) 3.18(\mathrm{t}, J 6.8$ $\mathrm{Hz}, 2 \mathrm{H}), 3.82(\mathrm{t}, J 6.8 \mathrm{~Hz}, 2 \mathrm{H}), 7.81(\mathrm{~s}, 1 \mathrm{H}), 8.19(\mathrm{~s}, 1 \mathrm{H}), 8.74(\mathrm{~s}, 1 \mathrm{H}), 9.53(\mathrm{~s}, 1 \mathrm{H}), 10.41(\mathrm{~s}, 1 \mathrm{H}) .{ }^{13} \mathrm{C} N M R(100$ $\left.\mathrm{MHz}, \mathrm{DMSO}-d_{6}\right) 36.7,49.8\left(\mathrm{CH}_{2}\right), 118.0,127.5,132.5,154.3\left(\mathrm{CH}_{\text {arom }}\right), 124.7,130.6,135.3,138.5,155.4\left(\mathrm{C}_{\mathrm{arom}}\right)$, 189.5 (CHO). Mp: 98-99 ${ }^{\circ} \mathrm{C}$. IR (ATR) 2082, 1691, 1615, 1445, 1396, 1340, $1291 \mathrm{~cm}^{-1} \mathrm{HRMS}$ (ESI+) calcd for $\mathrm{C}_{12} \mathrm{H}_{10}{ }^{35} \mathrm{CIN}_{4} \mathrm{O}(\mathrm{M}+\mathrm{H})^{+} 261.0538$, found 261.0533.

4-Chloro-2-iodo-5-\{[(tetrahydro-2H-pyran-2-yl)oxy]methyl\}benzaldehyde (7). Pyridinium $p$-toluenesulfonate (PPTS) (168 mg, $0.668 \mathrm{mmol})$ and dihydropyrane (DHP) $(0.86 \mathrm{~mL}, 10.1 \mathrm{mmol})$ were added to a solution of $A(2$ 
g, $6.76 \mathrm{mmol}$ ) in $\mathrm{CH}_{2} \mathrm{Cl}_{2}(36 \mathrm{~mL})$. The reaction mixture was stirred overnight at room temperature before removal of solvent under reduced pressure. Water was added before extraction with EtOAc. Organic layers were washed with brine, dried $\left(\mathrm{MgSO}_{4}\right)$ and concentrated under reduced pressure after filtration. The crude material was purified by flash chromatography using EtOAc/cyclohexane (1:6) yielding compound 7 (2.57 g, $6.75 \mathrm{mmol}$, quant.) as a white solid. TLC $\mathrm{R}_{f}=0.7$ (EtOAc/Cyclohexane 1:4). ${ }^{1} \mathrm{H} \mathrm{NMR}\left(400 \mathrm{MHz}, \mathrm{DMSO}-d_{6}\right)$ 1.47$1.73(\mathrm{~m}, 6 \mathrm{H}), 3.41-3.48(\mathrm{~m}, 1 \mathrm{H}), 3.71-3.74(\mathrm{~m}, 1 \mathrm{H}), 4.53(\mathrm{~d}, J 14.0 \mathrm{~Hz}, 1 \mathrm{H}), 4.70(\mathrm{~d}, J 14.0 \mathrm{~Hz}, 1 \mathrm{H}), 4.75(\mathrm{t}, J 4.0$ $\mathrm{Hz}, 1 \mathrm{H}), 7.89(\mathrm{~s}, 1 \mathrm{H}), 8.19(\mathrm{~s}, 1 \mathrm{H}), 9.94(\mathrm{~s}, 1 \mathrm{H}) .{ }^{13} \mathrm{C}$ NMR $\left(100 \mathrm{MHz}, \mathrm{DMSO}-d_{6}\right)$ 18.8, 24.9, 30.0, 61.4, $64.9\left(\mathrm{CH}_{2}\right)$, 97.9 (CH), 129.7, $140.0\left(\mathrm{CH}_{\text {arom }}\right), 99.7,133.9,137.1,138.5$ (C arom), 194.5 (CHO). Mp: 80-82 ${ }^{\circ} \mathrm{C}$. IR (ATR) 2936, 1686, 1582, $1450 \mathrm{~cm}^{-1}$. HRMS (ESI+) calcd for $\mathrm{C}_{13} \mathrm{H}_{15}{ }^{35} \mathrm{ClIO}_{3}(\mathrm{M}+\mathrm{H})^{+} 402.9568$, found 402.9569 .

4-Chloro-2-(4-hydroxybut-1-yn-1-yl)-5-\{[(tetrahydro-2H-pyran-2-yl)oxy]methyl\}benzaldehyde (8). To a solution of $7(1.0 \mathrm{~g}, 2.63 \mathrm{mmol})$ and but-3-yn-1-ol $(0.50 \mathrm{~mL}, 6.50 \mathrm{mmol})$ in $\mathrm{Et}_{3} \mathrm{~N}(10 \mathrm{~mL}), \mathrm{under}$ argon atmosphere, were added $\mathrm{PdCl}_{2}\left(\mathrm{PPh}_{3}\right)_{2}(36 \mathrm{mg}, 0.052 \mathrm{mmol})$ and Cul $(20 \mathrm{mg}, 0.105 \mathrm{mmol})$. The reaction mixture was heated at $50{ }^{\circ} \mathrm{C}$ for $2 \mathrm{~h}$ before solvent evaporation under reduced pressure. The crude material was purified by flash chromatography using EtOAc/cyclohexane (1:4 to 1:3) yielding compound 8 (748 mg, $2.32 \mathrm{mmol}, 88 \%)$ as an orange oil. TLC $\mathrm{R}_{f}=0.25$ (EtOAc/cyclohexane 1:4). ${ }^{1} \mathrm{H}$ NMR (400 MHz, DMSO- $\left.d_{6}\right)$ 1.49$1.77(\mathrm{~m}, 6 \mathrm{H}), 2.66(\mathrm{t}, J 6.6 \mathrm{~Hz}, 2 \mathrm{H}), 3.48-3.51(\mathrm{~m}, 1 \mathrm{H}), 3.62(\mathrm{q}, J 6.6 \mathrm{~Hz}, 2 \mathrm{H}), 3.74-3.80(\mathrm{~m}, 1 \mathrm{H}), 4.59(\mathrm{~d}, J 14.0$ $\mathrm{Hz}, 1 \mathrm{H}), 4.75(\mathrm{~d}, J 14.0 \mathrm{~Hz}, 1 \mathrm{H}), 4.78(\mathrm{t}, J 3.2 \mathrm{~Hz}, 1 \mathrm{H}), 4.98(\mathrm{t}, J 6.0 \mathrm{~Hz}, 1 \mathrm{H}), 7.71(\mathrm{~s}, 1 \mathrm{H}), 7.92(\mathrm{~s}, 1 \mathrm{H}), 10.38(\mathrm{~s}$, 1H). ${ }^{13} \mathrm{C}$ NMR $(100 \mathrm{MHz}$, DMSO-d $)$ 18.9, 23.6, 24.9, 30.0, 59.3, 61.4, $65.0\left(\mathrm{CH}_{2}\right), 97.9(\mathrm{CH}), 127.0,133.2$ $\left(\mathrm{CH}_{\text {arom }}\right), 75.0,97.8$ (C), 126.8, 134.2, 136.8, 137.7 (C arom), 190.8 (CHO). IR (ATR) 3433-3400, 2936, 2184, 2256, 1686, $1341 \mathrm{~cm}^{-1}$. HRMS (ESI+) calcd for $\mathrm{C}_{17} \mathrm{H}_{20}{ }^{35} \mathrm{ClO}_{4}(\mathrm{M}+\mathrm{H})^{+} 323.1045$, found 323.1040 .

2-(6-Chloro-7-\{[(tetrahydro-2H-pyran-2-yl)oxy]methyl\}isoquinolin-3-yl)ethan-1-ol (9). In a sealed tube, a solution of $8(181 \mathrm{mg}, 0.56 \mathrm{mmol})$ in $1.6 \mathrm{~mL}$ of $\mathrm{MeOH} / \mathrm{NH}_{3}(7 \mathrm{~N})$ was heated at $130{ }^{\circ} \mathrm{C}$ for $15 \mathrm{~min}$ in a microwave oven $(75 \mathrm{~W})$. The solvent was removed under reduced pressure. The crude product was purified by flash chromatography using EtOAc/cyclohexane (90:10 to 100:0 to EtOAc/MeOH 99:1), yielding compound 9 (177 mg, $0.55 \mathrm{mmol}, 98 \%)$ as an orange solid. TLC $\mathrm{R}_{f}=0.33$ (EtOAc/cyclohexane 7:3). ${ }^{1} \mathrm{H} \mathrm{NMR}(400 \mathrm{MHz}$, DMSO- $\left.d_{6}\right) 1.50-1.80(\mathrm{~m}, 6 \mathrm{H}), 3.01(\mathrm{t}, J 6.8 \mathrm{~Hz}, 2 \mathrm{H}) 3.50-3.54(\mathrm{~m}, 1 \mathrm{H}), 3.81(\mathrm{q}, J 5.6 \mathrm{~Hz}, 2 \mathrm{H}), 3.83-3.86(\mathrm{~m}, 1 \mathrm{H})$, $4.66(\mathrm{t}, J 5.2 \mathrm{~Hz}, 1 \mathrm{H}), 4.73(\mathrm{~d}, J 13.6 \mathrm{~Hz}, 1 \mathrm{H}), 4.82(\mathrm{t}, J 6 \mathrm{~Hz}, 1 \mathrm{H}), 4.87(\mathrm{~d}, J 13.6 \mathrm{~Hz}, 1 \mathrm{H}), 7.64(\mathrm{~s}, 1 \mathrm{H}), 8.07(\mathrm{~s}, 1 \mathrm{H})$, $8.19(\mathrm{~s}, 1 \mathrm{H}), 9.31(\mathrm{~s}, 1 \mathrm{H}) .{ }^{13} \mathrm{C} \mathrm{NMR}\left(100 \mathrm{MHz}, \mathrm{DMSO}-d_{6}\right)$ 19.0, 25.0, 30.1, 41.1, 60.6, 61.4, $65.8\left(\mathrm{CH}_{2}\right), 97.9(\mathrm{CH})$, 117.5, 125.8, 127.6, $151.8\left(\mathrm{CH}_{\text {arom }}\right), 125.1,134.4,134.8,135.7,153.8$ (Carom). Mp: $102-104{ }^{\circ} \mathrm{C}$. IR (ATR) 32222942, 2869, 1685, 1586, 1452, $1212 \mathrm{~cm}^{-1}$. HRMS (ESI ) calcd for $\mathrm{C}_{17} \mathrm{H}_{21}{ }^{35} \mathrm{CINO}_{3}(\mathrm{M}+\mathrm{H})^{+} 322.1205$, found 322.1210 .

2-(6-Chloro-7-\{[(tetrahydro-2H-pyran-2-yl)oxy]methyl\}isoquinolin-3-yl)ethyl methanesulfonate (10). Et ${ }_{3} \mathrm{~N}$ $(0.52 \mathrm{~mL}, 3.729 \mathrm{mmol})$ and methanesulfonyl chloride $(0.36 \mathrm{~mL}, 4.661 \mathrm{mmol})$ were added slowly to a cooled (0 $\left.{ }^{\circ} \mathrm{C}\right)$ solution of $9(1.0 \mathrm{~g}, 3.107 \mathrm{mmol})$ in $\mathrm{CH}_{2} \mathrm{Cl}_{2}(1.6 \mathrm{~mL})$. The reaction mixture was stirred at room temperature for $24 \mathrm{~h}$ before removal of solvent under reduced pressure. Water was added before extraction with EtOAc. Organic layers were washed with brine, dried $\left(\mathrm{MgSO}_{4}\right)$ and concentrated under reduced pressure after filtration. The crude material was purified by flash chromatography using EtOAc/cyclohexane (8:2 to 9:1) yielding compound $10\left(1.171 \mathrm{~g}, 2.928 \mathrm{mmol}\right.$, yield $94 \%$ ) as a yellow solid. TLC $\mathrm{R}_{f}=0.45$ (EtOAc/cyclohexane 7:3). ${ }^{1} \mathrm{H}$ NMR (400 MHz, DMSO-d $)_{6}$ 1.46-1.87 (m, 6H), $3.11(\mathrm{~s}, 3 \mathrm{H}), 3.29(\mathrm{t}, J 6.4 \mathrm{~Hz}, 2 \mathrm{H}), 3.51-3.54(\mathrm{~m}, 1 \mathrm{H})$, 3.80-3.84 (m, $1 \mathrm{H}), 4.65(\mathrm{t}, J 6.4 \mathrm{~Hz}, 2 \mathrm{H}), 4.70(\mathrm{~d}, J 13.2 \mathrm{~Hz}, 1 \mathrm{H}), 4.83(\mathrm{t}, J 6.0 \mathrm{~Hz}, 1 \mathrm{H}), 4.89(\mathrm{~d}, J 13.2 \mathrm{~Hz}, 1 \mathrm{H}), 7.73$ $(\mathrm{s}, 1 \mathrm{H}), 8.10(\mathrm{~s}, 1 \mathrm{H}), 8.23(\mathrm{~s}, 1 \mathrm{H}), 9.36(\mathrm{~s}, 1 \mathrm{H},) .{ }^{13} \mathrm{C} \mathrm{NMR}\left(100 \mathrm{MHz}, \mathrm{DMSO}-d_{6}\right) 36.60\left(\mathrm{CH}_{3}\right), 19.0,25.0,30.1$, 36.62, 61.4, 65.7, $69.3\left(\mathrm{CH}_{2}\right), 97.9(\mathrm{CH}), 118.2,126.0,127.7,152.1\left(\mathrm{CH}_{\text {arom }}\right), 125.4,135.1,135.2,135.7,150.9$ (Carom). Mp: $84-86{ }^{\circ} \mathrm{C}$. IR (ATR) 2943, 2869, 1685, 1586, $1452 \mathrm{~cm}^{-1}$. HRMS (ESI+) calcd for $\mathrm{C}_{18} \mathrm{H}_{23}{ }^{35} \mathrm{CINO}_{5} \mathrm{~S}$ $(\mathrm{M}+\mathrm{H})^{+} 400.0980$, found 400.0985 . 
2-[6-Chloro-7-(hydroxymethyl)isoquinolin-3-yl]ethyl methanesulfonate (11). To a solution of 10 (551 mg, $1.378 \mathrm{mmol}$ ) in acetone $(7 \mathrm{~mL})$ was added a $2 \mathrm{M}$ aqueous $\mathrm{HCl}$ solution $(3.45 \mathrm{~mL}, 6.89 \mathrm{mmol}$ ) at room temperature. The solution was stirred for $5 \mathrm{~h}$ at this temperature before evaporation of the solvent. A saturated aqueous $\mathrm{NaHCO}_{3}$ solution was added to reach $\mathrm{pH}=9$. Product was extracted with EtOAc. Combined organic phases were dried over $\mathrm{MgSO}_{4}$ and concentrated under reduced pressure. The crude material was purified by flash chromatography using EtOAc/MeOH 100:0 to 98:2 yielding compound 11 (415 mg, 1.314 mmol, 95\%) as a white solid. TLC $R_{f}=0.3$ (EtOAc). ${ }^{1} \mathrm{H}$ NMR (400 MHz, DMSO-d $\left.)_{6}\right) 3.11(\mathrm{~s}, 3 \mathrm{H}), 3.28(\mathrm{t}, J 6.4 \mathrm{~Hz}$, $2 \mathrm{H}), 4.66(\mathrm{t}, J 6.4 \mathrm{~Hz}, 2 \mathrm{H}), 4.72(\mathrm{~d}, J 5.4 \mathrm{~Hz}, 2 \mathrm{H}), 5.66(\mathrm{t}, J 5.4 \mathrm{~Hz}, 1 \mathrm{H}), 7.72(\mathrm{~s}, 1 \mathrm{H}), 8.06(\mathrm{~s}, 1 \mathrm{H}), 8.23(\mathrm{~s}, 1 \mathrm{H}), 9.35$ (s, 1H). ${ }^{13} \mathrm{C}$ NMR (100 MHz, DMSO-d $) 36.61\left(\mathrm{CH}_{3}\right), 36.68,60.5,69.4\left(\mathrm{CH}_{2}\right), 118.1,125.56,126.1,152.0\left(\mathrm{CH}_{\text {arom }}\right)$, 125.54, 134.6, 135.4, 139.0, 150.6 (C arom). Mp: 70-72 ${ }^{\circ} \mathrm{C}$. IR (ATR) 3584-2931, 2162, 1686, $1585,1451 \mathrm{~cm}^{-1}$. HRMS (ESI+) calcd for $\mathrm{C}_{13} \mathrm{H}_{15}{ }^{35} \mathrm{CINO}_{4} \mathrm{~S}(\mathrm{M}+\mathrm{H})^{+} 316.0405$, found 316.0411 .

2-(6-Chloro-7-formylisoquinolin-3-yl)ethyl methanesulfonate (12). Using similar procedure as described for 3: $11\left(411 \mathrm{mg}, 1.302 \mathrm{mmol}\right.$ ) and $\mathrm{MnO}_{2}(565 \mathrm{mg}, 6.508 \mathrm{mmol})$ were heated in $\mathrm{CHCl}_{3}(20 \mathrm{~mL})$ at reflux for $24 \mathrm{~h}$. After filtration of the mixture over Celite ${ }^{\circledR}$ pad and washing with EtOAc the crude material was purified by flash chromatography using EtOAc/cyclohexane 8:2 yielding compound 12 (299 mg, $0.953 \mathrm{mmol}, 73 \%$ ) as a pale yellow powder. TLC $R_{f}=0.40$ (EtOAc/cyclohexane 8:2). ${ }^{1} \mathrm{H}$ NMR (400 MHz, DMSO- $\left.d_{6}\right) 3.13(\mathrm{~s}, 3 \mathrm{H}), 3.34(\mathrm{t}, \mathrm{J}$ $6.4 \mathrm{~Hz}, 2 \mathrm{H}), 4.68(\mathrm{t}, J 6.4 \mathrm{~Hz}, 2 \mathrm{H}), 7.82(\mathrm{~s}, 1 \mathrm{H}), 8.22(\mathrm{~s}, 1 \mathrm{H}), 8.76(\mathrm{~s}, 1 \mathrm{H}), 9.55(\mathrm{~s}, 1 \mathrm{H}), 10.42(\mathrm{~s}, 1 \mathrm{H}) .{ }^{13} \mathrm{CNMR}(100$ $\left.\mathrm{MHz}, \mathrm{DMSO}-d_{6}\right) 36.6\left(\mathrm{CH}_{3}\right), 36.9,69.1\left(\mathrm{CH}_{2}\right), 118.2,127.5,132.6,154.3\left(\mathrm{CH}_{\text {arom }}\right), 124.8,130.7,135.3,138.5$, 154.1 (C arom), 189.5 (CO). Mp: 130-132 ${ }^{\circ} \mathrm{C}$. IR (ATR) 2330, 1686, 1618, 1587, 1447, $1339 \mathrm{~cm}^{-1}$. HRMS (ESI+) calcd for $\mathrm{C}_{13} \mathrm{H}_{13}{ }^{35} \mathrm{CINO}_{4} \mathrm{~S}(\mathrm{M}+\mathrm{H})^{+} 314.0248$, found 314.0239 .

2-(6-Chloro-7-formyl-5-nitroisoquinolin-3-yl)ethyl methanesulfonate (13). To a solution of 12 (295 mg, 0.942 mmol) in $2.1 \mathrm{~mL}$ concentrated $\mathrm{H}_{2} \mathrm{SO}_{4}$ at room temperature was slowly added $65 \% \mathrm{HNO}_{3}$ solution $(78 \mu \mathrm{L}, 1.13$ $\mathrm{mmol})$. The reaction was heated at $50{ }^{\circ} \mathrm{C}$ overnight and finally poured on crushed ice/water. The solution was neutralized with portions of solid $\mathrm{NaHCO}_{3}$ to reach $\mathrm{pH}=9$. Product was extracted with EtOAc and combined organic phases were dried over $\mathrm{MgSO}_{4}$ and concentrated under reduced pressure. The crude material was purified by flash chromatography using $\mathrm{CH}_{2} \mathrm{Cl}_{2} /$ EtOAc 9:1 to 8:2 yielding compound 13 (260 mg, $0.725 \mathrm{mmol}$, 77\%) as a pale yellow powder. TLC: $\mathrm{R}_{f}=0.4\left(\mathrm{CH}_{2} \mathrm{Cl}_{2} /\right.$ EtOAc 9:1). ${ }^{1} \mathrm{H}$ NMR (400 MHz, DMSO-d $) 3.13(\mathrm{~s}, 3 \mathrm{H}), 3.41$ $(t, J 6.4 \mathrm{~Hz}, 2 \mathrm{H}), 4.69(\mathrm{t}, J 6.4 \mathrm{~Hz}, 2 \mathrm{H}), 7.70(\mathrm{~s}, 1 \mathrm{H}), 9.03(\mathrm{~s}, 1 \mathrm{H}), 9.75(\mathrm{~s}, 1 \mathrm{H}), 10.38(\mathrm{~s}, 1 \mathrm{H}) .{ }^{13} \mathrm{C} \mathrm{NMR}(100 \mathrm{MHz}$, DMSO-d $\left.d_{6}\right) 36.6\left(\mathrm{CH}_{3}\right), 36.8,68.8\left(\mathrm{CH}_{2}\right), 112.1,134.5,154.8\left(\mathrm{CH}_{\text {arom }}\right), 124.6,127.3,129.6,130.3,145.1,157.2$ (C arom), 187.9 (CHO). Mp: 142-143 ${ }^{\circ} \mathrm{C}$. IR (ATR) 1693, 1615, 1534, 1325, $1168 \mathrm{~cm}^{-1}$. HRMS (ESI+) calcd for $\mathrm{C}_{13} \mathrm{H}_{12}{ }^{35} \mathrm{ClN}_{2} \mathrm{O}_{6} \mathrm{~S}(\mathrm{M}+\mathrm{H})^{+}$359.0099, found 359.0099.

10-Nitro-8-vinylpyrido[3,4-g]quinazolin-2-amine (14). Using standard procedure as described, ${ }^{1}$ a CEM microwave tube was charged with $13(193 \mathrm{mg}, 0.538 \mathrm{mmol})$, guanidine carbonate $(126 \mathrm{mg}, 0.699 \mathrm{mmol})$ and DMF (4 mL, peptide synthesis grade). Argon was bubbled through the solution for 20 min. The tube was irradiated in a CEM microwave at $300 \mathrm{~W}$ for $45 \mathrm{~s}$ at $166^{\circ} \mathrm{C}$. Water was added and product was extracted with EtOAc (large volume). Combined organic phases were washed with water and saturated brine solution, dried over $\mathrm{MgSO}_{4}$ and evaporated under reduced pressure. The crude material was purified by flash chromatography using EtOAc/cyclohexane 8:2 to 10:0 and finally EtOAc/MeOH 95:5 to 90:10 yielding compound 14 (95 mg, $0.355 \mathrm{mmol}, 66 \%$ ) as a brown powder. TLC $\mathrm{R}_{f}=0.5$ (EtOAc/cyclohexane 9:1). ${ }^{1} \mathrm{H} \mathrm{NMR}$ (400 MHz, DMSO-d 6 ) 5.62 (dd, J $10.8 \mathrm{~Hz}, J 2 \mathrm{~Hz}, 1 \mathrm{H}$ ), 6.51 (dd, J $16.8 \mathrm{~Hz}, J 2 \mathrm{~Hz}, 1 \mathrm{H}$ ), 7.04 (dd, J $16.8 \mathrm{~Hz}, J 10.8$ $\mathrm{Hz}, 1 \mathrm{H}), 7.46$ (s, 1H), 7.95 (br s, 1H), 8.02 (br s, 1H), 8.95 (s, 1H), $9.51(\mathrm{~s}, 1 \mathrm{H}), 9.55(\mathrm{~s}, 1 \mathrm{H}) .{ }^{13} \mathrm{C} \mathrm{NMR}(100 \mathrm{MHz}$, DMSO- $\left.d_{6}\right) 119.2\left(\mathrm{CH}_{2}\right.$ alkene $), 109.9\left(\mathrm{CH}_{\text {alkene }}\right), 134.0,136.2,155.2,165.7\left(\mathrm{CH}_{\text {arom }}\right), 120.4,121.4,129.3,136.6$, 142.1, 151.5, 161.3 (C (arom). Mp > $250^{\circ} \mathrm{C}$. IR (ATR) 3551-2698, 1666, 1612, 1574, 1503, $1288 \mathrm{~cm}^{-1} . \mathrm{HRMS}$ (ESI+) 
calcd for $\mathrm{C}_{13} \mathrm{H}_{10} \mathrm{~N}_{5} \mathrm{O}_{2}(\mathrm{M}+\mathrm{H})^{+} 268.0829$, found 268.0821 .

5-[5-Chloro-2-formyl-4-(hydroxymethyl)phenyl]pent-4-ynenitrile (15). To a solution of A (700 mg, $2.36 \mathrm{mmol}$ ) in triethylamine $(14 \mathrm{~mL})$, under argon atmosphere, were successively added Cul (18 $\mathrm{mg}, 0.094 \mathrm{mmol}$ ), $\mathrm{PdCl}_{2}\left(\mathrm{PPh}_{3}\right)_{2}$ (33 mg, $0.047 \mathrm{mmol}$ ) and 4-pentynenitrile $(530 \mu \mathrm{L}, 5.902 \mathrm{mmol})$. The mixture was stirred at $50{ }^{\circ} \mathrm{C}$ for $3 \mathrm{~h}$. The solvent was removed in vacuo and the crude material was purified by flash chromatography using EtOAc/cyclohexane (4:6 to 2:1) yielding compound 15 (543 mg, $2.20 \mathrm{mmol}, 93 \%$ ) as a white solid. TLC $\mathrm{R}_{f}=0.3$ (EtOAc/cyclohexane 2:3). ${ }^{1} \mathrm{H}$ NMR (400 MHz, DMSO-d $\left.)\right) 2.89(\mathrm{t}, J 2.5 \mathrm{~Hz}, 4 \mathrm{H}), 4.59(\mathrm{~d}, J 5.5 \mathrm{~Hz}, 2 \mathrm{H}), 5.65$ (t, J 5.7 $\mathrm{Hz}, 1 \mathrm{H}), 7.66(\mathrm{~s}, 1 \mathrm{H}) ; 8.00(\mathrm{~s}, 1 \mathrm{H}), 10.42(\mathrm{~s}, 1 \mathrm{H}) .{ }^{13} \mathrm{C} N M R\left(100 \mathrm{MHz}, \mathrm{DMSO}-d_{6}\right)$ 16.0, 16.4, $59.8\left(\mathrm{CH}_{2}\right), 76.5,95.6$ (C alkyne), $119.7(\mathrm{CN}), 125.2,134.3,136.8,141.2\left(\mathrm{C}_{\text {arom }}\right), 126.0,132.9\left(\mathrm{CH}_{\text {arom }}\right), 190.7$ (CO). Mp: $111-113{ }^{\circ} \mathrm{C} . \mathrm{IR}$ (ATR) 3263, $3002-2782,2250,1684,1598,1395 \mathrm{~cm}^{-1}$. HRMS (ESI+) calcd for $\mathrm{C}_{13} \mathrm{H}_{11}{ }^{35} \mathrm{CINO}_{2}(\mathrm{M}+\mathrm{H})^{+} 248.0478$, found 248.0473 .

3-[6-Chloro-7-(hydroxymethyl)isoquinolin-3-yl]propanenitrile (16). Using the same procedure as described for 9: 15 (537 mg, $2.18 \mathrm{mmol}), \mathrm{MeOH} / \mathrm{NH}_{3}(5.8 \mathrm{~mL}$ ). Flash chromatography using EtOAc/MeOH (100:0 to 98:2), yielding compound 16 (378 mg, $1.53 \mathrm{mmol}, 70 \%)$ as a brown oil which was dissolved in a minimum of acetone and cyclohexane leading to a greenish solid after evaporation. TLC $\mathrm{R}_{f}=0.4$ (EtOAc). ${ }^{1} \mathrm{H} \mathrm{NMR}(400 \mathrm{MHz}$, DMSOd $d_{6} 2.99(\mathrm{t}, J 7.0 \mathrm{~Hz}, 2 \mathrm{H}), 3.17(\mathrm{t}, J 7.1 \mathrm{~Hz}, 2 \mathrm{H}), 4.72(\mathrm{~d}, J 4.7 \mathrm{~Hz}, 2 \mathrm{H}), 5.68(\mathrm{t}, J 5.5 \mathrm{~Hz}, 1 \mathrm{H}), 7.73(\mathrm{~s}, 1 \mathrm{H}), 8.07(\mathrm{~s}$, $1 \mathrm{H}), 8.24(\mathrm{~s}, 1 \mathrm{H}), 9.36(\mathrm{~s}, 1 \mathrm{H}) .{ }^{13} \mathrm{C} N M R\left(100 \mathrm{MHz}, \mathrm{DMSO}-d_{6}\right) 16.2,32.5,60.5\left(\mathrm{CH}_{2}\right), 117.3,125.57,126.1,152.1$ $\left(\mathrm{CH}_{\text {arom}}\right), 120.3$ (CN), 125.58, 134.6, 135.3, 138.9, 151.9 (Carom). Mp: $114-116{ }^{\circ} \mathrm{C}$. IR (ATR) 3305, $3088-2762$, $2246,1629,1423 \mathrm{~cm}^{-1}$. HRMS (ESI+) calcd for $\mathrm{C}_{13} \mathrm{H}_{12}{ }^{35} \mathrm{CIN}_{2} \mathrm{O}(\mathrm{M}+\mathrm{H})^{+} 247.0638$; found 247.0649 .

3-(6-Chloro-7-formylisoquinolin-3-yl)propanenitrile (17). To a solution of 16 (635 $\mathrm{mg}, 2.57 \mathrm{mmol})$ in $\mathrm{CHCl}_{3}(26$ $\mathrm{mL}$ ) was added $\mathrm{MnO}_{2}(672 \mathrm{mg}, 7.72 \mathrm{mmol})$. The mixture was stirred at reflux for $5 \mathrm{~h}$, filtered through a pad of Celite ${ }^{\circledR}$ and washed with EtOAc. The filtrate was concentrated in vacuo. The crude material was triturated with cyclohexane and diisopropyl ether yielding compound $17(571 \mathrm{mg}, 2.33 \mathrm{mmol}, 90 \%)$ as a white solid after filtration. TLC $\mathrm{R}_{f}=0.75$ (EtOAC). RMN ${ }^{1} \mathrm{H}\left(400 \mathrm{MHz}, \mathrm{DMSO}-d_{6}\right) 3.02(\mathrm{t}, J 7.1 \mathrm{~Hz}, 2 \mathrm{H}), 3.23(\mathrm{t}, J 7.1 \mathrm{~Hz}, 2 \mathrm{H}), 7.83$ $(\mathrm{s}, 1 \mathrm{H}), 8.23(\mathrm{~s}, 1 \mathrm{H}), 8.77(\mathrm{~s}, 1 \mathrm{H}), 9.56(\mathrm{~s}, 1 \mathrm{H}), 10.43(\mathrm{~s}, 1 \mathrm{H}) .{ }^{13} \mathrm{C} N M R\left(100 \mathrm{MHz}, \mathrm{DMSO}-d_{6}\right) 16.0,32.6\left(\mathrm{CH}_{2}\right)$, 117.6, 127.6, 132.5, 154.4 ( $\left.\mathrm{CH}_{\text {arom }}\right), 120.2$ (CN), 124.8, 130.7, 135.4, 138.5, 155.2 (C arom), 189.5 (CHO). Mp: 145 $-147{ }^{\circ} \mathrm{C}$. IR (ATR) $3175-2845,2241,1750,1560,1447 \mathrm{~cm}^{-1} \mathrm{HRMS}(\mathrm{ESI}+)$ calcd for $\mathrm{C}_{13} \mathrm{H}_{10}{ }^{35} \mathrm{CIN}_{2} \mathrm{O}(\mathrm{M}+\mathrm{H})^{+}$ 245.0482, found 245.0502 .

3-(6-Chloro-7-formyl-5-nitroisoquinolin-3-yl)propanamide (18). To a solution of isoquinoline 17 (250 mg, 1.02 $\mathrm{mmol}$ ) in $\mathrm{H}_{2} \mathrm{SO}_{4}(2.5 \mathrm{~mL})$ was added portionwise $\mathrm{KNO}_{3}(155 \mathrm{mg}, 1.53 \mathrm{mmol})$ over $15 \mathrm{~min}$. Additional $\mathrm{KNO}_{3}(26$ $\mathrm{mg}$ ) was added after two days stirring at room temperature. Upon completion of the reaction (3 days, TLC control) the mixture was poured in a minimum of crushed ice/water and the aqueous solution was made alkaline by addition of solid $\mathrm{NaHCO}_{3}$. The product was extracted several times with EtOAc. Organic layers were dried $\left(\mathrm{MgSO}_{4}\right)$ and concentrated under reduced pressure after filtration, yielding compound 18 (267 mg, 0.86 $\mathrm{mmol}, 85 \%$ ) as a pale yellow solid. TLC $\mathrm{R}_{f}=0.4$ (Acetone $\left./ \mathrm{CH}_{2} \mathrm{Cl}_{2} 1: 1\right)$. RMN ${ }^{1} \mathrm{H}\left(400 \mathrm{MHz}, \mathrm{DMSO}-d_{6}\right) 2.58(\mathrm{t}, J 7.5$ $\mathrm{Hz}, 2 \mathrm{H}$ ), 3.17 (t, J $7.5 \mathrm{~Hz}, 2 \mathrm{H}), 6.80$ (br s, NH), 7.35 (br s, NH), 7.52 (s, 1H), $9.00(\mathrm{~s}, 1 \mathrm{H}), 9.70$ (s, $1 \mathrm{H}), 10.37$ (s, 1H). ${ }^{13} \mathrm{C}$ NMR (100 MHz, DMSO-d $\left.d_{6}\right) 33.2,34.0\left(\mathrm{CH}_{2}\right), 110.6,134.4,154.5\left(\mathrm{CH}_{\text {arom }}\right), 124.3,127.1,129.6,129.9$, 145.0, 161.4 (C arom), 173.1, 187.9 (CO). Mp: 210-211 ${ }^{\circ} \mathrm{C}$ IR (ATR) 3524-2952, 1694, 1669, 1619, 1539, 1432, $1279 \mathrm{~cm}^{-1}$ HRMS (ESI+) calcd for $\mathrm{C}_{13} \mathrm{H}_{11}{ }^{35} \mathrm{CIN}_{3} \mathrm{O}_{4}(\mathrm{M}+\mathrm{H})^{+} 308.0433$, found 308.0432 .

3-(2-Amino-10-nitropyrido[3,4-g]quinazolin-8-yl)propanamide (19). A suspension of compound 18 (50 mg, $0.16 \mathrm{mmol}$ ) and guanidine carbonate $(40 \mathrm{mg}, 0.22 \mathrm{mmol})$ in DMA $(2 \mathrm{~mL})$ was degassed with argon for $30 \mathrm{~min}$ then heated at $111^{\circ} \mathrm{C}$ (oil bath) for a total time of $25 \mathrm{~min}$. After completion of the reaction, EtOAc was added. The resulting slurry was filtered on a pad of Celite ${ }^{\circledR}$ and washed with EtOAc. The organic layer was washed 
with water and brine, dried $\left(\mathrm{MgSO}_{4}\right)$ and the volatiles were removed under reduced pressure. The residue was purified by flash chromatography using $\mathrm{CH}_{2} \mathrm{Cl}_{2} / \mathrm{MeOH}$ (from 95:5 to 90:10), yielding tricyclic compound 19 (19 $\mathrm{mg}, 0.042 \mathrm{mmol}, 26 \%)$ as a golden yellow solid. TLC $\mathrm{R}_{f}=0.3\left(\mathrm{CH}_{2} \mathrm{Cl}_{2} / \mathrm{MeOH}\right.$ 95:5, eluted twice). ${ }^{1} \mathrm{H} \mathrm{NMR}(400$ $\left.\mathrm{MHz}, \mathrm{DMSO}-d_{6}\right) 2.56(\mathrm{t}$, under solvent signal), $3.09(\mathrm{t}, J 7.5 \mathrm{~Hz}, 2 \mathrm{H}), 6.80(\mathrm{br} \mathrm{s}, \mathrm{NH}), 7.32(\mathrm{~s}, 1 \mathrm{H}), 7.35(\mathrm{br} s, \mathrm{NH})$, 7.95 (br s, NH), 8.03 (br s, NH), $8.95(\mathrm{~s}, 1 \mathrm{H}), 9.49(\mathrm{~s}, 1 \mathrm{H}), 9.55(\mathrm{~s}, 1 \mathrm{H}) .{ }^{13} \mathrm{C}$ NMR Not recorded due to low solubility. Mp > $285^{\circ} \mathrm{C}$. IR (ATR) 3420 - 3040, 1701, 1674, 1620, 1546, $1413 \mathrm{~cm}^{-1}$. HRMS (ESI+) calcd for $\mathrm{C}_{14} \mathrm{H}_{13} \mathrm{~N}_{6} \mathrm{O}_{3}(\mathrm{M}+\mathrm{H})^{+} 313.1044$, found 313.1043. HPLC: purity $>96 \%, \lambda=240 \mathrm{~nm}, \mathrm{t}_{\mathrm{R}}=4.7 \mathrm{~min}$.

3-(2,10-Diaminopyrido[3,4-g]quinazolin-8-yl)propanamide (20). To a suspension of compound 19 (15 mg, $0.048 \mathrm{mmol}$ ) in $15 \mathrm{~mL}$ of anhydrous THF was added palladium on charcoal ( $10 \% \mathrm{wt}, 3 \mathrm{mg}, 0.003 \mathrm{mmol})$. The mixture was stirred under 7 bars of $\mathrm{H}_{2}$ for 2 days, and filtered through Celite ${ }^{\circledR}$. The Celite ${ }^{\circledR}$ pad was washed several times with EtOAc. Combined filtrates were concentrated under reduced pressure to give compound 20 as a red solid (10 mg, $0.035 \mathrm{mmol}, 73 \%)$. TLC $\mathrm{R}_{f}=0.2\left(\mathrm{CH}_{2} \mathrm{Cl}_{2} / \mathrm{MeOH} 9: 1\right) .{ }^{1} \mathrm{H} \mathrm{NMR}\left(400 \mathrm{MHz}, \mathrm{DMSO}-d_{6}\right) 2.57(\mathrm{t}$, J $7.8 \mathrm{~Hz}, 2 \mathrm{H}$ ), 3.03 (t, J $7.8 \mathrm{~Hz}, 2 \mathrm{H}), 6.10$ (br s, NH $\mathrm{N}_{2}$ ), 6.77 (br s, NH), 6.97 (br s, NH), 7.35 (br s, NH), 7.80 (s, 1H),

$7.83(\mathrm{~s}, 1 \mathrm{H}), 8.48$ (br s, NH), $9.18(\mathrm{~s}, 1 \mathrm{H}), 9.32(\mathrm{~s}, 1 \mathrm{H}) .{ }^{13} \mathrm{C} N M R\left(100 \mathrm{MHz}, \mathrm{DMSO}-d_{6}\right) 33.5,34.9\left(\mathrm{CH}_{2}\right), 112.1$, 113.9, 154.4, $164.8\left(\mathrm{CH}_{\text {arom }}\right), 118.6,121.9,123.2,135.1,135.3,150.9,158.6$ ( $\left.\mathrm{C}_{\text {arom }}\right), 173.8$ (CO). Mp: $235{ }^{\circ} \mathrm{C}$ (dec.). IR (ATR) 3529-2515, 1665, 1608, 1548, $1388 \mathrm{~cm}^{-1}$. HRMS (ESI+) calcd for $\mathrm{C}_{14} \mathrm{H}_{15} \mathrm{~N}_{6} \mathrm{O}(\mathrm{M}+\mathrm{H})^{+} 283.1302$ found 283.1296.

\section{Acknowledgments}

The authors F.A., F.G. and P.M. thank the Auvergne Region (Jeune Chercheur Program) for funding as well as the French Ministry of Higher Education and Research for Y.J.E. PhD fellowship. Aurélie Job is sincerely acknowledged for HPLC analysis. Authors B.J., B.B., S.B., S.R. thank the Cancéropôle Grand Ouest (axis: natural sea products in cancer treatment), IBiSA (French Infrastructures in Life Science) and Biogenouest (Western France Life Science and Environment Core Facility Network) for supporting KISSf screening facility of FR2424 in Roscoff.

\section{Supplementary Material}

Copies of proton and carbon-13 NMR spectra of all newly synthesized molecules 4-20 are presented as supporting information in Supplementary Materials. Readers will be able to access this supporting information using the link "Supplementary Material" in the journal issue contents page.

\section{References}

1. Esvan, Y. J.; Zeinyeh, W.; Boibessot, T.; Nauton, L.; Théry, V.; Knapp, S.; Chaikuad, A.; Loaëc, N.; Meijer, L.; Anizon, F.; Giraud, F.; Moreau, P. Eur. J. Med. Chem. 2016, 118, 170-177. https://doi.org/10.1016/i.ejmech.2016.04.004

2. Zeinyeh, W.; Esvan, Y. J.; Nauton, L.; Loaëc, N.; Meijer, L.; Théry, V.; Anizon, F.; Giraud, F.; Moreau, P. Bioorg. Med. Chem. Lett. 2016, 26, 4327-4329.

https://doi.org/10.1016/i.bmcl.2016.07.032 
3. Zeinyeh, W.; Esvan, Y. J.; Josselin, B.; Baratte, B.; Bach, S.; Nauton, L.; Théry, V.; Ruchaud, S.; Anizon, F.; Giraud, F.; Moreau, P. Bioorg. Med. Chem. 2019, 27, 2083-2089.

https://doi.org/10.1016/j.bmc.2019.04.005

4. Tazarki, H.; Zeinyeh, W.; Esvan, Y. J.; Knapp, S.; Chatterjee, D.; Schröder, M.; Joerger, A. C.; Khiari, J.; Josselin, B; Baratte, B.; Bach, S.; Ruchaud, S.; Anizon, F.; Giraud, F.; Moreau, P. Eur. J. Med. Chem. 2019, 166, 304-317. https://doi.org/10.1016/i.ejmech.2019.01.052

5. Iyer, S.; Liebeskind, L. S. J. Am. Chem. Soc. 1987, 109, 2759-2770. https://doi.org/10.1021/ja00243a032

6. Dehnhardt C. M.; Megati, S.; Michalak, R. S.; Raveendranath, P. US20050070723, 2005; Chem. Abstr. 2005, 142, 355160.

7. Alfonsi, M.; Dell'Acqua, M.; Facoetti, D.; Arcadi, A.; Abbiati, G.; Rossi, E. Eur. J. Org. Chem. 2009, 28522862.

https://doi.org/10.1002/ejoc.200900014

8. Yoshida, Y.; Barrett, D.; Azami, H.; Morinaga, C.; Matsumoto, S.; Matsumoto, Y.; Takasugi, H. Bioorg. Med. Chem. 1999, 7, 2647-2666.

https://doi.org/10.1016/S0968-0896(99)00203-5

9. Saito, Y.; Matsumoto, K.; Bag, S. S.; Ogasawara, S.; Fujimoto, K.; Hanawa, K.; Saito, I. Tetrahedron 2008, 64, 3578-3588.

https://doi.org/10.1016/i.tet.2008.01.091

10. Bordwell, F. G.; Garbisch Jr., E. W. J. Am. Chem. Soc. 1960, 82, 3588-3598.

https://doi.org/10.1021/ja01499a029

11. Zhou, Z.-L.; Kher, S. M.; Cai, S. X.; Whittemore, E. R.; Espitia, S. A.; Hawkinson, J. E.; Tran, M.; Woodward, R. M.; Weber, E.; Keana, J. F. W. Bioorg. Med. Chem. 2003, 11, 1769-1780. https://doi.org/10.1016/S0968-0896(03)00059-2

12. Nowrouzi, N.; Mehranpour, A. M.; Bashiri, E.; Shayan, Z. Tetrahedron Lett. 2012, 53, 4841-4842. https://doi.org/10.1016/i.tetlet.2012.06.126

13. Hajipour, A. R.; Ruoho, A. E. Tetrahedron Lett. 2005, 46, 8307-8310. https://doi.org/10.1016/j.tetlet.2005.09.178

14. Riego, J. M.; Sedin, Z.; Zaldívar, J. M.; Marziano, N. C.; Tortato, C. Tetrahedron Lett. 1996, 37, 513-516. https://doi.org/10.1016/0040-4039(95)02174-4

15. Shea, K. M.; Jaquinod, L.; Smith, K. M. J. Org. Chem. 1998, 63, 7013-7021. https://doi.org/10.1021/jo980965p

16. Smith, N. W.; Dzyuba, S. V. Arkivoc 2010, 7, 10-18. https://doi.org/10.3998/ark.5550190.0011.702

17. Štefane, B.; Požgan, F.; Sosič, I.; Gobec, S. Tetrahedron Lett. 2012, 53, 1964-1967. https://doi.org/10.1016/j.tetlet.2012.02.017

18. Bach, S.; Knockaert, M.; Reinhardt, J.; Lozach, O.; Schmitt, S.; Baratte, B.; Koken, M.; Coburn, S. P.; Tang, L.; Jiang, T.;Liang, D.-C.; Galons, H.; Dierick, J. F.; Pinna, L. A.; Meggio, F.; Totzke, F.; Schächtele, C.; Lerman, A. S.; Carnero, A.; Wan, Y.; Gray, N.; Meijer, L. J. Biol. Chem. 2005, 280, 31208-31219. https://doi.org/10.1074/jbc.M500806200 